University of Wollongong

Research Online

Faculty of Informatics - Papers (Archive)

Faculty of Engineering and Information

Sciences

21-6-2006

\title{
Understanding the Adoption of Clusters by SMEs using Innovation Theory
}

Y. R. Kim Chung

University of Wollongong

William Tibben

University of Wollongong,wjt@uow.edu.au

Follow this and additional works at: https://ro.uow.edu.au/infopapers

Part of the Physical Sciences and Mathematics Commons

\section{Recommended Citation}

Kim Chung, Y. R. and Tibben, William: Understanding the Adoption of Clusters by SMEs using Innovation Theory 2006.

https://ro.uow.edu.au/infopapers/545

Research Online is the open access institutional repository for the University of Wollongong. For further information contact the UOW Library: research-pubs@uow.edu.au 


\title{
Understanding the Adoption of Clusters by SMEs using Innovation Theory
}

\begin{abstract}
SMEs-clustering has been of considerable interest over the last decade and is associated with regional development. The Australian government advocates the formation of SMEs cluster thereby encouraging SMEs to achieve competitive advantage through globalisation. However, the notion of SMEs clusters involves some issues in terms of its adoption by SMEs. Firstly, most academic research shows that SMEs cluster has been treated as a phenomenon in the economy and that its foundation lacks a theoretical perspective. Secondly, there is a lack of understanding of SME clusters in general. Much of the literature on SMEs and clusters has primarily addressed the benefit of industrial clusters; however, the process of how SMEs adopt clusters is given less attention. This study leads to a more refined understanding of SME clusters with an emphasis on its adoption by SMEs. It utilises Roger's Innovation theory to explore the processes involved in the adoption of SMEs cluster by SMEs and also the advantages and disadvantages obtained by doing so. The novelty of this study lies in the assumption that the cluster idea is an innovation per se. In particular, we adopt Roger's S-shaped innovation curve model to investigate how SMEs adopt the cluster idea as an innovation. We look to see if the pattern of joining the cluster in time follows Roger's S-shaped curve. A case study methodology method will be used to collect data from SMEs within a cluster in Australia. It is expected that the data gathered will be analysed to suggest implications as to how SMEs can sustain competitive advantage within SME clusters.

\section{Disciplines}

Physical Sciences and Mathematics

\section{Publication Details}

This paper was originally published as: Kim Chung, YR \& Tibben, W, Understanding the Adoption of Clusters by SMEs using Innovation Theory, The 3rd IEEE International Conference on Management of Innovation and Technology (ICMIT 2006), Singapore, 21-23 June 2006, 1, 389-393. Copyright 2006 IEEE.
\end{abstract}




\title{
Understanding the Adoption of Clusters by SMEs using Innovation Theory
}

\author{
Ye Ryung Kim Chung, William Tibben \\ School of Information Technology and Computer Science \\ Faculty of Informatics \\ University of Wollongong, Australia \\ yrk48@uow.edu.au,wjt@uow.edu.au
}

\begin{abstract}
SMEs-clustering has been of considerable interest over the last decade and is associated with regional development. The Australian government advocates the formation of SMEs cluster thereby encouraging SMEs to achieve competitive advantage through globalisation. However, the notion of SMEs clusters involves some issues in terms of its adoption by SMEs. Firstly, most academic research shows that SMEs cluster has been treated as a phenomenon in the economy and that its foundation lacks a theoretical perspective. Secondly, there is a lack of understanding of SME clusters in general. Much of the literature on SMEs and clusters has primarily addressed the benefit of industrial clusters; however, the process of how SMEs adopt clusters is given less attention. This study leads to a more refined understanding of SME clusters with an emphasis on its adoption by SMEs. It utilises Roger's Innovation theory to explore the processes involved in the adoption of SMEs cluster by SMEs and also the advantages and disadvantages obtained by doing so. The novelty of this study lies in the assumption that the cluster idea is an innovation per se. In particular, we adopt Roger's S-shaped innovation curve model to investigate how SMEs adopt the cluster idea as an innovation. We look to see if the pattern of joining the cluster in time follows Roger's S-shaped curve. A case study methodology method will be used to collect data from SMEs within a cluster in Australia. It is expected that the data gathered will be analysed to suggest implications as to how SMEs can sustain competitive advantage within SME clusters.
\end{abstract}

\section{INTRODUCTION}

In an economy where knowledge transforms into innovation to become the principal driving force for success, firms must understand the innovation cycle and its diffusion process to capitalise on the innovation. Small and medium-sized enterprises (SMEs) are one of the primary sources of innovation and it plays a key role in the development of the emerging knowledge based economy. However in the current economy, one of the issues that SMEs face is competition against large international or national companies. For SMEs to survive in this globalisation era, they intend to form clusters. Although the Australian federal government eagerly supports SMEs to form SMEs cluster, there are issues surrounding the creation of clusters. In light of such issues, it is necessary to understand the process of the creation of clusters by SMEs.

This study utilises Roger's Innovation theory to explore the processes involved in the adoption of SMEs cluster by SMEs and also the advantages and disadvantages obtained by doing so. The novelty of this study lies in the assumption that the cluster idea is an innovation per se. In particular, we adopt the $\mathrm{S}$ shaped innovation curve model developed by Rogers to investigate how SMEs adopt the cluster idea as an innovation. Survey methods will be used to collect data from the SMEs in Australia. It is expected that the data gathered will be analysed to better understand the formation of clusters and the implications this has for competitive.

In the next section we present the background of the study by discussing the definition of a SME cluster and detailing how SMEs clusters have gained considerable interest over the past few years. The following sections consist of the literature review on the topic of innovation, followed by the objectives of the study, expected outcome, methodology and future directions for the research.

\section{BACKGROUND OF THE STUDY}

Burgelman, Maidique et al argue that SMEs need to focus on innovation - referred to as application of skills, expertise and knowledge to work to remain competitive [2]. However, the innovative capacity of SMEs per se is limited. Therefore, a proposed strategy to foster innovation is for SMEs to form clusters. This allows SMEs to enter into global competition fostered with local elements of competitive advantage. SME clusters allow SMEs to compete globally leveraging on better access to information and specialised resources, flexibility and rapid adoption of innovations [3]. The core of the thesis therefore centres upon the argument that SMEs cluster could be created by factors such as force-environments, identical business purpose, and obvious benefit and so on; however, much of the literature shows that the formation of SMEs cluster is natural phenomenon. Furthermore, it is also argued that it is quite difficult to create SME clusters [4].

Given the above, the purpose of this research is to use Roger's Model of Innovation Diffusion to understand adoption of clusters by SMEs. The following questions motivate the study:

- What factors motivates early SME adopters to join cluster? 
- What factors motivated recent SME adopters to join cluster?

- Does the adoption of the cluster by SMEs follow the $\mathrm{S}$ curve proposed by Rogers?

-What benefits (material or knowledge-based) do they currently derive from membership of cluster?

- Is industrial clustering a natural phenomenon? Or can it be created?

An in-depth exploration through a single case study methodology will be conducted with SMEs those of which already belong to a cluster. The case findings will provide a rich insight into the innovation-diffusion process of each SME. It will then be used to understand how SMEs are capable of adopting clusters as an innovation and what benefits are being achieved by being in a cluster in terms of knowledge management initiatives, supporting core competencies and sustaining competitive advantage in the globalization era.

\section{A. A Working Definition of SMEs Clusters for the Study}

SME-clustering has been of considerable interest over the last decade and is associated with regional development. SMEs cannot be treated as miniature versions of larger firms and hence, its problems cannot be solved by using knowledge management methods applicable to large firms [3]. The Australian government advocates the formation of SMEs cluster thereby encouraging SMEs to achieve competitive advantage through globalisation. However, the notion of SMEs clusters involves some issues in terms of its adoption by SMEs. Firstly, most academic research show that SME cluster has only been treated as a phenomenon in the economy and that its foundation lacks a theoretical perspective [5]. Secondly, there is a lack of understanding of SME clusters in general [6;7] Therefore, this study may lead to a more refined understanding of SME clusters with an emphasis on its adoption by SMEs. Much of the literature on SMEs and clusters has primarily addressed the benefit of industrial clusters; however, the process of how SMEs adopt clusters is given less attention.

The notion of 'cluster' can be applied to the service and manufacturing industries, to high-technology agglomerations as well as to concentrations of lower technology industries. However, as no specific definition of clusters has been arrived at, the use of the concept of cluster in the literature has been quite flexible. Steiner argued that clusters bear a character like "the discreet charm of obscure objects of desire" [8]. This multi-dimensionality and ambiguous character of clusters create problems of hypothetical and experiential definition, as well as for methodological research. It becomes hard to distinguish cluster externalities from general urbanization economies and infrastructural externalities [9].

In spite of the arguments posed above, most researchers commonly refer to the concept of the cluster by discussing the cluster definition suggested by Porter [10]. Porter's concept of 'cluster' originated in his comparative work on international competitiveness [10], where he argued that the successful exporting firms in a variety of different countries experienced great success because those firms belonged to a successful group of rivals within related industries. The process of clustering, and the intense interchange among industries in the cluster, also works best where the industries involved are geographically concentrated.

Porter's more recent work has continued this theme, arguing that while co-location is not sufficient for cluster formation, it 'supercharges' and magnifies the power of domestic rivalry which is the major urge to continuous innovation and improvement. Porter now defines clusters as "geographic concentrations of interconnected companies, specialised suppliers, service providers, firms in related industries, and associated institutions in particular fields that compete but also co-operate" [11]. John, Michelle et al also defines clusters "as one of the popular models of interconnected-firm networking" [12]. In this study, we combine the views of Porter [10] and John, Michelle et al [12] to construct a working definition of SME Cluster as follows:

"SME clusters are interconnected (inter-networked) firms based on common business goals, and are composed of SMEs in related industries and connected in particular fields that compete but also co-operate, and are preferably located in some degree of proximity."

The scope of the location may vary from a single city, state, country, to being virtual, because a company may have networks with other companies across states or countries. Based on the scope of the location, clusters are also formed varietally [7]. Therefore, in this study, clusters are considered not only in terms of its geographical and physical proximity but also its virtual proximity between the SMEs within the SME cluster. Borrowing the concept from social networks, the ties between the SMEs (represented by people, leaders or groups) may be measured by frequency of communication or interaction, closeness, intimacy, reciprocity of services to each other by using communication technology [13].

\section{B. Innovation}

Much of the literature focuses on the benefits obtained by being in a cluster where the formation of the cluster appears as a given However, there is lack of understanding of the process of formation of clusters. In this study, we use Innovation and Diffusion Theory as our theoretic context to understand cluster formation. The core theory underpinning the research is the Innovation Diffusion Theory [14].

Innovation is defined as an idea, practice or product that is perceived as new by the potential adopters even if it had existed earlier elsewhere [14]. This definition is limited in the sense that an innovation can be as simple as coming up with a new idea, but not actually putting the idea into practice. 
The theory of innovation diffusion claims that people usually postpone their decision-making when there is uncertainty or risk. However Roger argues that each individual's innovation decision can be made on personal characteristics and this variety actually makes diffusion possible. When the decision of adopting an innovation has not been convinced to individual members then usually innovation decision follows a 5-step process, namely: 1) Knowledge 2) Persuasion 3) Decision 4) Implementation 5) Confirmation [14]. For a successful innovation, the adopter distributions follow a bell-shaped curve, the derivative of the S-shaped diffusion curve, over time and approach normality.

Diffusion scholars split in to this bell-shaped curve to characterize five categories of system member innovativeness, where innovativeness is defined as the degree to which an individual is relatively earlier in adopting new ideas than other members of a system. These groups are: 1) innovators, 2) early adopters, 3) early majority, 4) late majority, and 5) laggards. The personal characteristics and interaction of these groups illuminates the aforementioned domino effect. The S-shaped curve is depicted below:

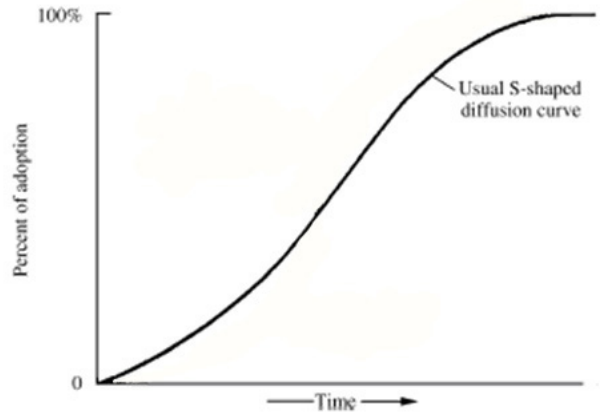

Fig. 1. The rate of adoption for innovation Source [14]

The process of innovation is closely linked with creativity, discovery and invention. Creativity is essentially the source of all inventions, and ultimately all innovations. Considered as a way of thinking and as a driver for change, Williams views creativity as something that is novel (ie. bearing a unique value), practical (ie. usable, solving or fulfilling an existing problem or need) and understandable (ie. able to be replicated or used by others) [1]. He models creativity as the core element of innovation in an eight-step process consisting of the following stages. Note that the first four stages relates to the 'birth' and the development of new ideas, while the last four relates to the application of the ideas. 1) Awareness and interests. 2) Preparation and understanding. 3) Absorption and incubation. 4) Inspiration and illumination. 5) Testing and verification. 6) Refinement and adjustment. 7) Acceptance and commitment. 8) Implementation. These eight stages can be linked and depicted in the diagram below:

Williams describes innovation as the art of applying the new and the better [1]. More specifically, it is the process by

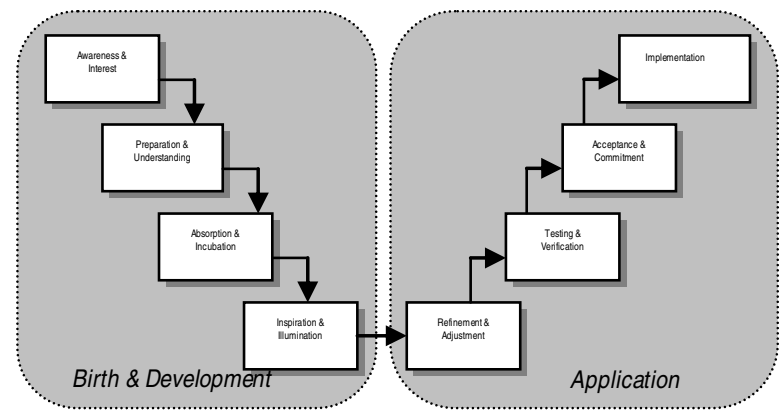

Fig 2: Williams' model of Creativity as a process [1]

which entrepreneurs are catalysts for change by converting opportunities into marketable realities. In the latter definition, emphasis is placed on the creation of new wealth, rather than new knowledge, and eventual successful implementation ideas. It is important to realise that the core element of innovation is creativity, which stems from invention and discovery. Also Roger suggested that diffusion is the process of an innovation being communicated by certain channel over time between the members of a social system. Williams is more concrete wishing to see tangible improvements. In the management perspective most firms adopt innovation with a view to yield higher profits; therefore William's notion of innovation will be adopted in this study.

In this study, we propose understanding the innovation diffusion process by considering the process of adopting SMEs cluster as an innovation itself. In order for us to understand whether the process of cluster adoption remains an innovation or not, we will compare the results from the data obtained from the case study against the $S$-shape curve. If reasonable data from the case study shows a similar S-shape curve along with characteristics of the innovation then one may infer that the SMEs cluster adoption notion has been adopted as innovation to SMEs.

\section{AIM, EXPECTED OUTCOME, SIGNIFICANCE}

The objectives of this study are plenty:

- To understand the notion of SME clusters and process of SME-clusters formation using Roger's S-shape Model.

- To understand the benefits obtained by SMEs which are part of the SME cluster.

- To understand challenges and complexities related to SME clusters as being related to innovation and learning.

- To suggest implications as to how SMEs can sustain competitive advantage within SME clusters.

\section{METHODOLOGY}

In particular, the study is exploratory because it attempts to unravel information in order to form a richer picture of SMEs. 
As mentioned earlier, we adopt a case study approach of studying SMEs as primary units within a SME cluster within New South Wales, Australia. At the current time of writing this paper, the SMEs have agreed to participate in the study and we are at a stage to administer the surveys. The following sections outline the selection of SMEs, leading to the research design.

\section{SELECTION OF SMES}

This study is conservative and confess to the fact that its is a pilot/exploratory Hence, it was necessary to choose the SMEs Cluster that would serve as best representations of the target population of the study.

Although the domain of this research pertains to the SMEs based in Australia, in this study, we will hypothetically refer to the SMEs Cluster as "A-Floors" to protect the privacy of the company. For the purpose of our study, it was necessary to select a SME cluster which has already started to evolve and develop over the years with a lot more potential for growth.

The definition of SMEs and Cluster as postulated in previous section served as a corrective measure and a stringent validation tool to ensure that the SMEs Cluster selected for the study suits the model of the research. The SME cluster "A-Floors" consists of 100 stores located Australia wide, with each store annual turnover being approx AUD\$ 1 Million. "A-Floors" has been in business for over 20 years, and started from early 1980's by recruiting SMEs to join the cluster. Each store has been managed independently. However the executive committee is formed to over look the major decisions of the cluster. This committee is headed by the founder, who is current director of the organisation. Sub committees have also been set up, into function areas - marketing, finance, technology and products groups, such as nylon, wools, tiles, vinyl. The basic philosophy was that as more stores get together it will be better for them to gain buying power then being an individual SME. This company now has 100 stores and is one of the largest buying groups in Australia. There are regular company meeting every two month and there is a bi-annual meeting also. At least one representative is expected to attend from each SME. Figure 3.2 shows the current "A-Floors" structure

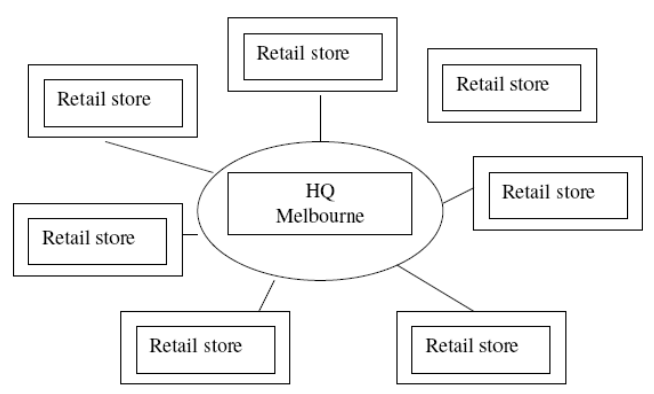

Fig 3 Current "A-Floors" structure

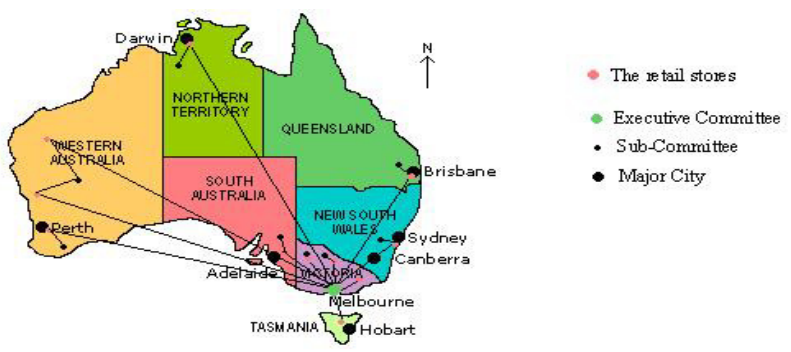

Fig 4 Geographical Structure Chart of A-Floors

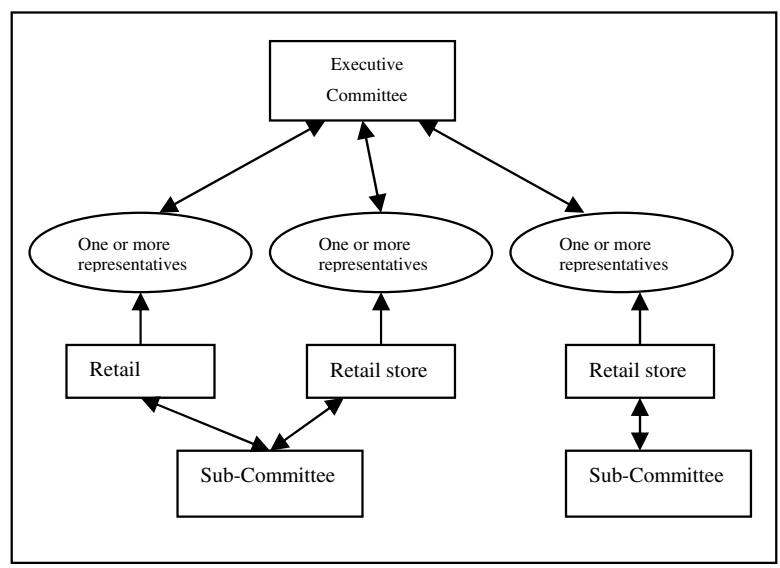

Fig 5 Reporting Structure Chart of A-Floors

The selected SMEs cluster was contacted by email to ask for permission to administer the survey in the company. Upon acceptance to participate in the study, we will engage in the distribution of the surveys and to the SME representatives through the head office along with an explanation about the study.

\section{CONCLUSION - FUTURE DIRECTIONS}

This study contributes to the growing literature of SMEs Clusters in the context of SMEs innovation diffusion as a cluster-adopting notion. By drawing on literature about SMEs and SMEs cluster from a wide variety of academic journals, theses and government reports, a good overview of SMEs Clusters and its significance in the Australian economy has been presented.

We have reviewed several definitions of innovation. It was identified that creativity, invention and discovery were the main sources of innovation. In an era where globalization affects the world and local economy, in order for SMEs to sustain competitive advantage, innovation is crucial. This study has therefore suggested that SMEs in Australia are adopting innovations in several forms, the one of interest in our study being the adoption of Cluster notion. The next 
phase in the research is to carry out the case study methodology and the administration of the survey to selected SMEs which are already a part of "A-Floors" (SMEs cluster).

In this study expect to understand the pattern of SMEs Innovation adoption and whether considering the cluster notion as innovation was valid idea or not. If it is so, it will be significant in terms of taking into consideration of the cluster notion as innovation for the first time. If the results confirm that SMEs adopt the notion of being in cluster as an innovation, then we will gain a new perspective of understanding the adoption of clusters by SMEs as an innovation diffusion process not only as natural phenomenon. This should give us room to understand further the existence of tipping point and opinion leaders in Roger's model of innovation diffusion.

\section{REFERENCES}

[1] Williams, A. (1999). Creativity, Invention \& Innovation. Sydney, Australia, Allen \& Unwin.

[2] Burgelman, R. A., Maidique, M. A., et al. (1996). Strategic Management of Technology and Innovation. Boston, Massachusetts, McGraw-Hill.

[3] Barnett, R. R. and Mackness, J. R. (1983). "An Action Research Study of Small Firms." Management Journal of Applied Systems 10: 63-83.

[4] Sverrisson, Á. (2000). "Technological Development in Networked SME Clusters." Private Sector Promotion in Developing Countries.

[5] Weitzel, T., Wendt, O., et al. (2003). "Network Effects and Diffusion Theory: Network Analysis in Economics." IT Standards and Standardization Research 1((2)): 1-21.

[6] Mytelka, L. and Farinelli, F. (2000). Local Clusters, Innovation Systems and Sustained Competitiveness. Rio de Janiero.

[7] Braun, P., McRae-Williams, P., et al. (2005). "Small Business Clustering: The Benefits of Local Network Learning."

[8] Steiner, M. (1998). Clusters and Regional Specialisation: On Geography, Technology and Networks. London, Pion.

[9] Harrison, B., Kelley, M., et al. (1996). "Innovative firm behaviour and local milieu." Economic Geography 72.

[10] Porter, M. E. (1990). The Competitive Advantage of Nations. London, Macmillan.

[11] Porter, M. (1998). "Clusters and the new economics of competition." Harvard Business Review November/December.

[12] John, V. B., Michelle, B., et al. (2003). Understanding and measuring the effect of social capital on knowledge transfer within clusters of small-medium enterprises. 16th Annual Conference of Small Enterprise Association of Australia and New Zealand, 28 September to 1 October, Ballarat, Enterprise Association of Australia and New Zealand.

[13] Granovetter, M. S. (1973). "The Strength of Weak Ties." The American Journal of Sociology 78(6).
[14] Rogers, E. (2003). Diffusion of Innovation. New York, USA, The Free Press. 